IZA DP No. 5810

The Decline of Early Retirement Pathways in the Netherlands: An Empirical Analysis for the Health Care Sector

Rob Euwals

Annemiek van Vuren

Daniel van Vuuren

June 2011 


\title{
The Decline of Early Retirement Pathways in the Netherlands: An Empirical Analysis for the Health Care Sector
}

\author{
Rob Euwals \\ CPB, Netspar and IZA \\ Annemiek van Vuren \\ $C P B$ \\ Daniel van Vuuren \\ $C P B$ and Netspar \\ Discussion Paper No. 5810 \\ June 2011 \\ IZA \\ P.O. Box 7240 \\ 53072 Bonn \\ Germany \\ Phone: +49-228-3894-0 \\ Fax: +49-228-3894-180 \\ E-mail: iza@iza.org
}

Any opinions expressed here are those of the author(s) and not those of IZA. Research published in this series may include views on policy, but the institute itself takes no institutional policy positions.

The Institute for the Study of Labor (IZA) in Bonn is a local and virtual international research center and a place of communication between science, politics and business. IZA is an independent nonprofit organization supported by Deutsche Post Foundation. The center is associated with the University of Bonn and offers a stimulating research environment through its international network, workshops and conferences, data service, project support, research visits and doctoral program. IZA engages in (i) original and internationally competitive research in all fields of labor economics, (ii) development of policy concepts, and (iii) dissemination of research results and concepts to the interested public.

IZA Discussion Papers often represent preliminary work and are circulated to encourage discussion. Citation of such a paper should account for its provisional character. A revised version may be available directly from the author. 
IZA Discussion Paper No. 5810

June 2011

\section{ABSTRACT}

\section{The Decline of Early Retirement Pathways in the Netherlands: An Empirical Analysis for the Health Care Sector}

Early retirement schemes and disability insurance in the Netherlands have both been reformed during the past decades. The reforms have increased incentives to continue working and have decreased the substitution between early retirement and disability. This study investigates the impact of the reforms on labour market exit probabilities. We use administrative data for workers in the Dutch health care sector between 1999 and 2006. We estimate a multinomial Logit model for transitions out of the labour force. The empirical results suggest that the reforms have been effective, as the labour market participation rate of the elderly has increased. The concept of substitute pathways into retirement seems less relevant today as the results confirm that disability insurance is closed off as an early retirement exit route.

JEL Classification: $\quad$ C35, J26

Keywords: early retirement, disability insurance, labour supply

Corresponding author:

Rob Euwals

CPB Netherlands Bureau of Economic Policy Analysis

P.O. Box 80510

2508 GM The Hague

The Netherlands

E-mail: r.w.euwals@cpb.nl

\footnotetext{
* The authors thank Rob Alessie, Marloes Lammers, Arthur van Soest, Elisabetta Trevisan, and participants at seminars at CPB and Netspar for comments. Stichting Instituut GAK is acknowledged for the provision of financial support, while PGGM/PFZW and Statistics Netherlands are acknowledged for the provision of data. The paper is part of the Netspar theme Pensions, Savings and Retirement.
} 


\section{Introduction}

The labour force participation rate of men aged 55 to 64 decreased substantially in many OECD countries during the 1970s and 1980s. Financial incentives, and in particular the high implicit tax when continuing to work, have played an important role (Gruber and Wise, 2004). Apart from the financial incentives, employees may have had a preference for early retirement because of the household situation, health or social norms. Furthermore, employers had a preference for early retirement as they wanted their unproductive workers to leave. Finally, governments of several countries used to have a preference for early retirement, as they believed that youth unemployment could be lowered through earlier retirement of the older workforce. ${ }^{2}$ Remarkably, the decline in labour force participation rates of men aged 55 to 64 was similar to that of France, Germany and the Netherlands, whereas labour market institutions were quite different (Duval, 2010). Such similar developments seem in line with the concept of "pathways into retirement". According to this concept, the preference for early labour market exit has led to early retirement through different exit routes which were close substitutes for each other. In other words, individual employees had the 'choice' between several exit routes, including early retirement, disability and unemployment. Push factors generated by the organisation of work have been essential in the rise of such substitute exit routes (Kohli and Rein, 1991; Riphahn, 1997; Larsen and Pedersen, 2008). However, from the 1990s onwards the social insurance and early retirement systems of several countries have been reformed. The concept of substitute pathways into early retirement may have lost importance during the last decade. In this study, we focus on the development of two major pathways for labour market exit in the Netherlands: early retirement and disability. ${ }^{3}$

This study is based on the general hypothesis that recent reforms, which aimed at increasing the participation rate of older workers, have led to a different functioning of institutions surrounding early retirement. Our first hypothesis is that the probability of inflow into early retirement and disability has decreased on individual level. As a consequence the probability to remain employed has increased. Our second and main hypothesis is that the

\footnotetext{
${ }^{2}$ The idea that early retirement reduces unemployment rests on the thought that the number of jobs is fixed. It is nowadays widely recognized that the thought is wrong (Barr and Diamond, 2009; Gruber and Wise, 2010).

${ }^{3}$ In this paper we disregard unemployment, as it hardly qualifies as a pathway during our period of study. The Dutch unemployment rate of elderly is about the same as for other age groups, and furthermore the Dutch unemployment rate is very low in an international perspective.
} 
reforms have stopped substitution between exit routes. In particular, disability insurance is not used anymore as a route for early retirement in the Netherlands. We discuss recent empirical evidence and, in a second step, investigate the hypotheses by applying multiple choice models to a new large administrative dataset for the Netherlands.

On the basis of the administrative data containing workers of the Dutch health care sector between 1999 and 2006, we provide evidence for both hypotheses. First, the inflow into early retirement and disability has decreased and the employment rate of older individuals increased. Second, the results are consistent with the hypothesis that disability is no longer used as an alternative early retirement route. Several empirical studies have shown that disability has served as an early exit route in the past. Our results confirm the hypothesis that the reforms have decreased substitution from early retirement schemes towards the disability scheme.

The remainder of the study is organised as follows. Section 2 provides an overview of the reforms of Dutch early retirement and disability schemes. The section contains figures showing that the aggregate inflow into early retirement and disability decreased substantially. Section 3 discusses previous research based on survey data for the 1980s and early 1990s. This research has shown that the concept of substitute pathways holds indeed for the Netherlands. In section 4 and 5, we discuss and employ administrative data of the Dutch health care pension fund between 1999 and 2006 to investigate the impact of the reforms on labour market exit probabilities. Section 6 concludes.

\section{Early retirement and disability insurance}

During the economically prosperous period starting about a decade after the Second World War, the Netherlands set up an extensive welfare state including a pension system and a public disability insurance scheme. The two most important elements in the pension system are the state pension, which is financed on a pay-as-you-go basis, and the occupational pension system, which is capital funded. During the economic crisis of the 1980s, the unions and employer organizations installed an early retirement scheme in addition to the existing arrangements. Soon it became clear that the pension and welfare system was not sustainable in the long run. A series of reforms followed. This section discusses the most important reforms in the early retirement and pension system and the disability insurance schemes. 


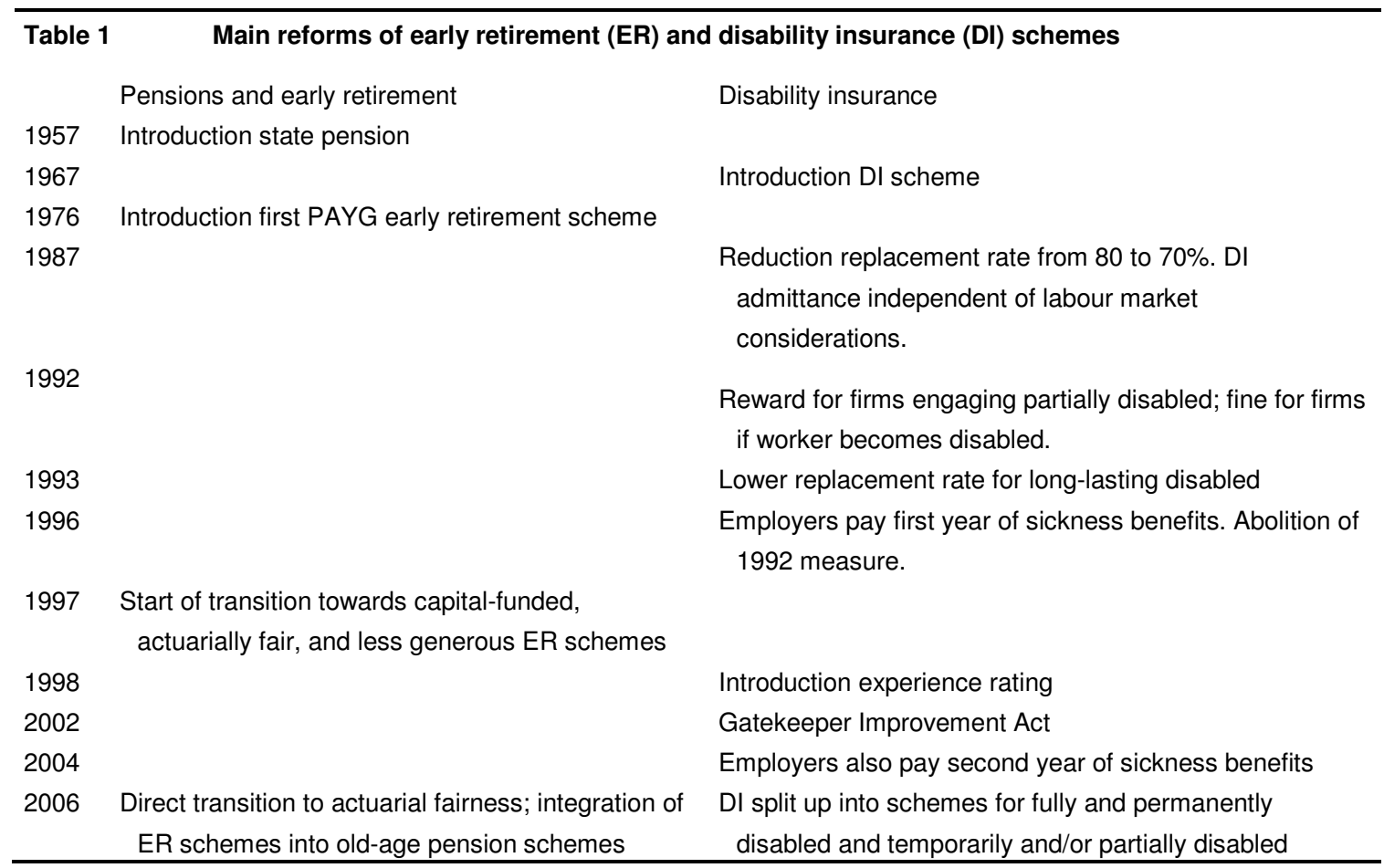

\subsection{Old age pension and early retirement}

The Dutch state pension system was installed in 1957 (Table 1). The statutory retirement age in the Dutch state pension system was and still is 65. From that age on, Dutch citizens that lived in the Netherlands from age 15 to 64 receive a state pension benefit. ${ }^{4}$ This first-pillar pension benefit guarantees an income of $70 \%$ of the minimum wage for singles, and $50 \%$ of the minimum wage for each member of a couple. The pension is financed on a pay-as-you-go basis, and pension benefits are not related to work history.

On top of the flat-rate benefit, most retired employees receive a mandatory occupational pension. They are capital funded and mostly defined-benefit pensions. Occupational pensions are subject to negotiations between unions and employer organisations. The government is involved in the occupational pensions in two ways. First, pension savings receive a special fiscal treatment. The taxation of the schemes is characterised as an EET-system (exempt-exempt-taxed). Contributions to the scheme are tax exempt, the returns on the assets in the capital funding system are exempt, and the pensions are taxed. Second, the government facilitates occupational pension schemes by extension to all workers in the concerning sector or firm. ${ }^{5}$ Agreements between unions and employer

\footnotetext{
${ }^{4}$ For each year spent abroad between the ages of 15 and 65 the state pension is lowered by $2 \%$.

${ }^{5}$ Collective labour agreements are either made at the firm level or at the sectoral level.
} 
organisations typically receive the 'generally binding' approval from the government, and hence the occupational pensions are mandatory for workers in the concerning firm or sector.

During the 1970s and the first half of the 1980s, many sectors of industry introduced early retirement schemes. The schemes were financed on a pay-as-you-go basis and were highly actuarially unfair. After reaching a certain age, a worker could retire and receive early retirement benefits of about $80 \%$ of the last earned wage in gross terms. Due to the progressive tax system and a continued accrual of old-age pension rights, the net replacement rate was typically higher than $80 \%$. Working one more year, and so postponing the early retirement benefit claim, would not lead to an increase in the replacement rate. As a result, the implicit tax rate on continuing to work for another year was about $100 \%$ for many workers, implying that work would not generate any additional income. Not too surprisingly, empirical studies show that the impact on the participation of elderly between the ages of 55 and 64 was strong (Kapteyn and de Vos, 1999, Gruber and Wise, 2004, Euwals, van Vuuren and Wolthoff, 2010).

The early retirement schemes are held responsible for a substantial part of the drop in the participation rate of men aged 55 to 64 . The drop in the participation rate of elderly was actually in line with the goal of the early retirement schemes. The Netherlands went through a severe economic crisis, and the explicit goal was to allow firms to lay off older workers in order to save jobs for the young. The schemes however became costly and doubts arose about the saving of jobs for the young. In 2007, about four out of ten individuals between the ages of 60 and 64 received an early retirement benefit.

During the 1990s, the unions and employer organisations agreed upon transforming the generous and actuarial unfair early retirement schemes into less generous and actuarially fair schemes. One goal was to remove the implicit tax on continuing to work. Another goal was to limit the costs. In most sectors of industry it was decided to implement transitional arrangements which could take more than ten years. The first transition started on April 1, 1997 for civil servants. For some sectors of industry the transition started later. The transition should have been completed in 2022. The installation of a new law on January 1, 2006 however considerably accelerated the transition.

Since January 1, 2006, early retirement schemes are integrated into the capital-funded occupational pension system. Before this date both systems were in principle independent. Within the new system early retirement before age 65 is still possible. The special fiscal treatment in case of retirement before age 65 stays in place as long as the pension benefit is 
adjusted actuarially fair. Some of the large Dutch pension funds allow for an early retirement benefit of about $70 \%$ of the average earned wage at age 63 .

Figure 1: Disability insurance recipients as a fraction of population age 20-64.

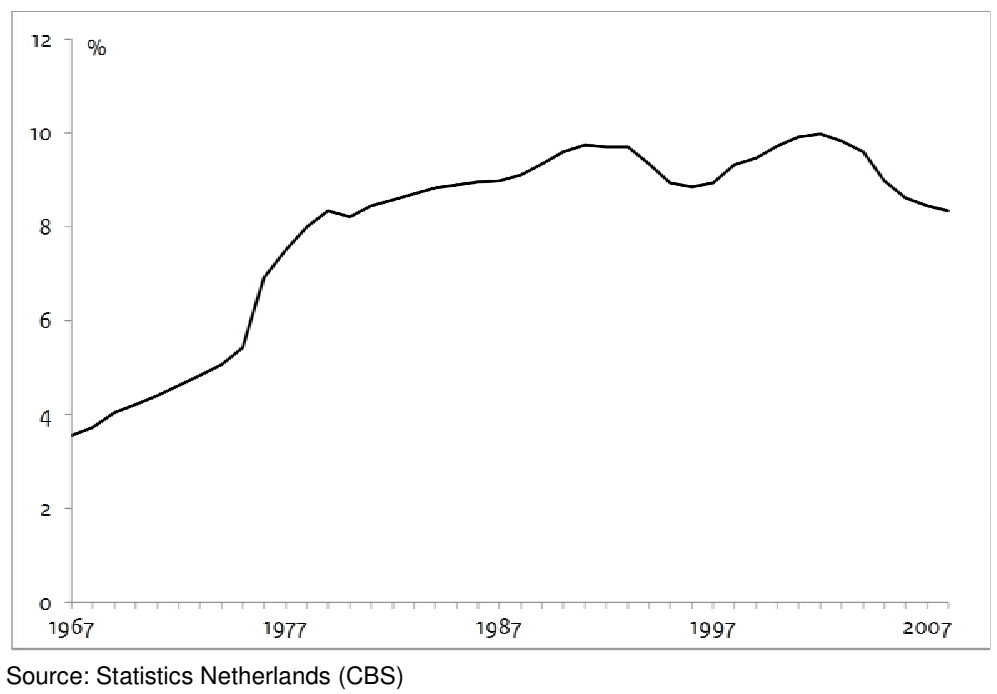

Figure 2: Pathways into early retirement in the Netherlands, men age 55-59 and 60-64
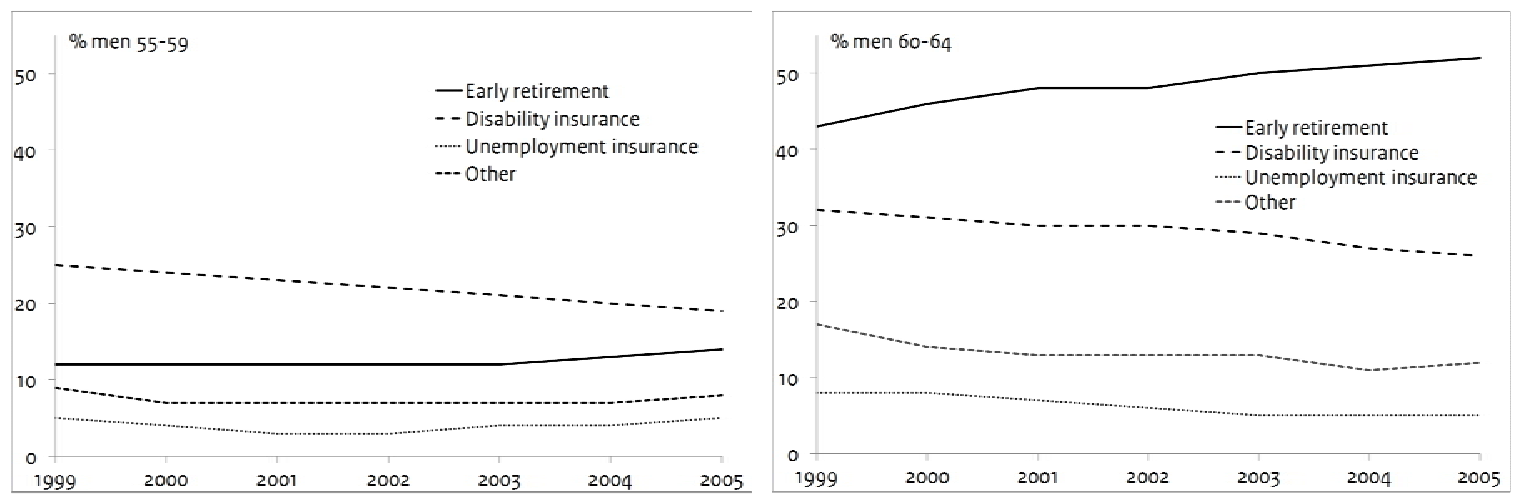

Source: Statistics Netherlands (CBS)

\subsection{Disability insurance}

The public disability insurance system was installed in 1967, ten years after the introduction of the state pension system (Table 1). All employees in the Netherlands are covered by this Disability Insurance (DI), regardless of their work history. The DI scheme insures workers who do not recover from sickness within two years. Any form of disability is insured, whether stemming from social or professional risk. Workers becoming disabled for at least $80 \%$ receive full DI benefits. Partially disabled, who are disabled for less than $80 \%$, receive pro rata benefits. A significant portion of the partially disabled is involved in gainful employment. Replacement rates of the disability benefits vary by firm or sector (Van Vuren 
and van Vuuren, 2007). In contrast to the DI schemes in many other western countries, the Dutch DI scheme lacks a minimum reference period. All workers are fully insured from the first working day.

During the 1970s the annual growth of the number of DI recipients was about 11 percent. This increase was much higher than expected at the introduction of the system. During the 1970s and most of the 1980s, benefits were $80 \%$ of final pay, entry conditions were weak, and enforcement by the public body was lax. To slow down the inflow and decrease the number of recipients many reforms took place starting in the late 1980s. In 1987, the replacement rate was reduced from 80 to $70 \%$ (Table 1). Moreover, labour market considerations would not play a role anymore in the disability assessment. However, the volume and cost reductions were not substantial. One of the most important reasons was that the replacement rate reduction was repaired in collective labour agreements.

More financial incentives were introduced to confront employees and employers with the financial consequences of the use of sickness and disability benefits. In 1992, a premium differentiation system for sickness benefits and a (not long-lived) no-claim bonus system were introduced. The system implied that employers had to pay a penalty for each employee entering DI. On the other hand, a firm employing a DI beneficiary for at least one year would receive a bonus. Until 1993, a fully disabled person received a wage-related benefit of unlimited duration. Since then, both the duration and the level of the benefit became dependent on the recipient's age and employment history. However, this loss in benefits was repaired for about four out of five employees through collective labour agreements (Social and Economic Council, 2002). A restricted own risk for employers for sickness benefits was introduced in 1994 in order to reduce absence through illness. Large firms became responsible for the continued payment of wages during the first six weeks of sickness, and small firms for the first two weeks. Since 1996 employers pay sickness benefits during the entire first year. The no-claim bonus system was replaced in 1998 by a system of experience rating. Firms could opt out of the public system to bear the risk themselves or to reinsure the risk with a private insurer.

Many policy reforms during the late 1990s and early 2000s aimed at achieving a more efficient administration. This has resulted in the merger of five different administrative offices into one public monopoly (UWV) which is responsible for the administration of all DI and unemployment benefits in the Netherlands. The 'Gatekeeper Improvement Act' was implemented in 2002, implying more stringent reintegration obligations of the employer and 
its employees. In order to be eligible for the DI, the public administrative office assesses whether both employer and employee have met the reintegration obligations.

The duration of the sickness benefit period has been extended from one to two years in 2004, increasing the financial incentive for employers to prevent disability. In 2006, the previous DI scheme (the so-called WAO) is replaced by two new schemes under the umbrella 'Income According to Capacity for Work Act' (WIA). The WIA focuses on the remaining capacity to earn income. It distinguishes between fully and long-lasting disabled and temporarily and/or partially disabled. The first group only contains former employees who are both fully and permanently incapacitated. ${ }^{6}$ They qualify for earnings-related benefits with a replacement rate of $75 \%$. The second group contains individuals who are partially disabled or temporarily fully disabled. They may either qualify for earnings-related benefits or benefits which are based on the minimum-wage level, depending the remaining work capacity and employment history. The benefit system includes a financial incentive for the DI recipient to use his remaining work capacity. Under the WIA, employees who become disabled for less than $35 \%$ are no longer insured.

Between 1967 and 1991 the share of DI recipients in the age group 20 to 64 increased from 3.5 to $9.7 \%$ (Figure 1). The aggregate data suggest that the adjustments in 1987 did not have an effect on the use of DI. The first drop occurs between 1993 and 1996, when a final level of $8.9 \%$ is reached. Next, the use of DI increases back again to the old level in 2001 and 2002. From then on, we see a downward trend until a share of $8.3 \%$ is reached in 2008 , which is the lowest share since 1982. The last three policy measures are held largely responsible for this decreasing trend, in particular the Gatekeeper Improvement Act and the increased financial responsibility of employers through the payment of sickness benefits.

The number of men receiving a disability benefit increased over time until the beginning of the 1990s (Figure 1). ${ }^{7}$ From the end of the 1990s, the main development for the 55-59 year old is a decrease of the share of DI recipients from 25 to 19\% (left panel of Figure 2). The other categories in the figure remain stable over time, so that employment has increased. The fraction of DI recipients among 60-64 year-old men decreased from 32 to $26 \%$ (right panel of Figure 2). In this age group, the fraction of individuals receiving an unemployment benefit or another benefit decreased by $8 \%$-points. At the same time the

\footnotetext{
${ }^{6}$ The disability degree in this group is between 80 and $100 \%$. Recovery is ruled out or cannot be expected within five years.

${ }^{7}$ We focus on men as developments for women are mainly driven by cohort effects (see Euwals et al., 2011).
} 
fraction of individuals retiring early rose by $9 \%$-points. Overall, the employment rate of the oldest age category has also increased.

\section{Literature overview on substitute pathways}

Already in the beginning of the 1990s, Kohli and Rein (1991) argued that the increase in early labour market exit during the 1970s and early 1980s was driven by a common trend: the slowdown in economic growth and the substantial increase in unemployment. So according to Kohli and Rein's concept, which we refer to as "pathways for labour market exit" or "pathways into early retirement", push factors generated by the organization of work were decisive in the rise of generous exit arrangements. A pathway can be defined as a combination of institutional arrangements to manage the transition process between exit from work and entry into the pension system. Many OECD countries developed one or more pathways into early retirement.

Institutional arrangements creating pathways for early retirement were often constructed for purposes other than early labour market exit. In France, unemployment insurance was a typical pathway; in Germany both unemployment and disability insurance; and in the Netherlands the disability insurance schemes. During the 1970s and 1980s, unemployment and disability insurance were made more easily accessible for older workers in many countries. In Sweden unemployed persons above age 63 would receive a disability pension without medical justification. Some countries facilitated early labour market exit through the old-age pension scheme. In Germany a work-history condition allowed workers to retire at age 63.

The empirical literature shows that the concept of substitute pathways applied to the Dutch labour market situation in the 1980s and early 1990s. Kerkhofs et al. (1999) estimate a competing risk model for the transition from work to early retirement, disability and unemployment for the years 1993-1995. The attractiveness of the different schemes is characterised by (i) the replacement rate, (ii) an eligibility indicator for the early retirement scheme, and (iii) a 'waiting time indicator' for the scheme. The schemes considered in this study are not actuarially adjusted over different retirement ages, implying that the estimated coefficients on the replacement rate represent an effect of the implicit tax rate on the labour force participation decision. The second and third indicator are likewise related to the lack of actuarial adjustment. Retirement before the early retirement eligibility age would mean a complete loss of entitlements. The authors find that high replacement rates in the disability and unemployment insurance schemes reduce the individual propensity to make use of the 
early retirement scheme. Second, they find that the early retirement scheme seems to be preferred over the two other schemes (after controlling for replacement rates). Yet, health is the most important determinant of transitions into disability, whereas financial incentives are the most important determinant of transitions into the official early retirement scheme. ${ }^{8}$ Using the same data set to estimate a structural dynamic model of retirement behaviour, Heyma (2004) finds that reforms in the early retirement schemes increase pressure on both disability and unemployment. The author concludes that policies aimed at changing attitudes towards retirement seem necessary to increase labour participation of the elderly.

In an earlier study, Woittiez et al. (1994) showed that early retirement and disability are preferred exit routes from the labour market, whereas unemployment insurance is subject to a so-called 'stigma effect'. Using data for the period 1986-1992, the authors find a clear but small substitution effect between the different exit routes. Simulations indicate that a reduction in the financial attractiveness of a scheme leads to a higher participation rate, and that spill-over effects to other schemes are present but limited in size. Using survey data for the 1990s and the early 20th century, Schils (2008) compares labour force exit rates for workers aged 50 to 65 in Germany, the UK and the Netherlands. The author distinguishes between three pathways: early retirement, social insurance - including both disability and unemployment - and 'inactivity' - i.e. not receiving any of these benefits. She concludes that early retirement and social insurance act as communicating vessels in Germany and in the Netherlands, but less so in the UK.

The current study does not investigate unemployment as a substitute pathway, but nevertheless there is also ample evidence for several countries for substitution between unemployment and disability insurance (Benitez-Silva et al., 2010). A substantial empirical literature has focussed on the degree of 'hidden unemployment' in the disability scheme in the Netherlands. Explicit estimates - ranging from 10 to 50\% - were provided by Aarts and de Jong (1992), Westerhout (1996), and Hassink et al. (1997). However, according to recent estimates, the many reforms during the 1990s and early 2000s have led to a substantial decline in the degree of hidden unemployment in disability enrolment to a point where there is almost no substitution left (Koning and van Vuuren, 2007; 2010). It may however still take several decades until the stock of disability recipients is freed from hidden unemployment.

The concept of substitute pathways seems to apply to many countries, even including the US. In the US, the DI enrolment rate for individuals aged 45 to 64 has increased from

\footnotetext{
${ }^{8}$ A similar result for the US was found by Bound et al. (1991).
} 
$4.5 \%$ in 1983 to $6.7 \%$ in 2005. In 2005, $12 \%$ of the 64 year old Americans were receiving DI benefits. A part of this increase is thought to be a direct consequence of the "pathways concept'. ${ }^{9}$ The 1983 Social Security reform reduced the generosity of public old-age pensions in the U.S. by both increasing the full retirement age and increasing the penalty for claiming benefits at the early retirement age of 62 . This has made the disability pathway to retirement relatively more attractive. Duggan et al. (2007) indeed find that disability enrolment has significantly increased as a consequence of the reform. Estimates indicate that each $\$ 5000$ decline in the present value of old-age pension benefits increased enrolment by $0.4 \%$-points for men and $0.8 \%$-points for women. According to the authors, the aggregate disability enrolment figure of 45 to 65 year olds has become more than a percentage point lower because of the reform. ${ }^{10}$ A similar effect was found in France, where pension reform has pushed up the use of disability insurance (Behaghel et al., 2010).

\section{Data}

The empirical evidence in this study is based on administrative data from the health care sector. Below we discuss the early retirement schemes in the sector and the data. A detailed discussion can be found in Euwals, Trevisan and van Vuren (2010).

\subsection{Early retirement schemes in the health care sector}

The sector underwent the reforms described in Section 2. The transition to an actuarially fair early retirement system started on January 1, 1999. The actuarial unfair scheme was gradually abolished and replaced by an actuarially fair scheme, the so-called FLEX scheme. The benefit level in the new scheme is based on work history. For almost all workers, the benefit level of the new scheme is substantially lower than that of the old scheme. Furthermore, early retirees no longer accrue old-age-pension-rights under the new scheme.

The sector introduced a transitional scheme to compensate workers who were close to eligibility for the old early retirement scheme. This so-called OBU early retirement scheme was installed for workers who were born before 1949, and who would have qualified for the

\footnotetext{
${ }^{9}$ Note that the official name of the American DI scheme is Social Security Disability Insurance (SSDI). Autor and Duggan (2003) link the increased use of DI to rising replacement rates for low-skilled workers, and Black et al. (2002) demonstrate that the recessions in 1991 and 2001 increased pressure on DI.

${ }^{10}$ An earlier study by Mitchell and Phillips (2000) concluded smaller spill-over effects. This study did however not exploit the actual changes in Social Security rights over different birth cohorts, and was not able to observe DI enrolment rates beyond the age of 60 for individuals affected by the reform.
} 
old scheme. ${ }^{11}$ The OBU-scheme is financially more attractive than the new scheme for almost all workers. The replacement rate is higher, and postponement of retirement results in a higher future benefit, which was not the case in the old scheme. However, after age 63 no actuarial adjustments are made. And during the period of early retirement members continue to build up old-age-pension-rights. The OBU-scheme was de facto abolished from January 1, 2006. Since then, the early retirement facilities are integrated into the old-age-pension scheme (Section 2.1).

\subsection{Administrative data}

The empirical analysis is based on administrative data from the pension fund of the health care sector, PFWZ (formerly PGGM). It is the second largest pension fund in the Netherlands, providing pension arrangements to more than 2 million (ex-)employees in the health and social work sector. The data cover the period 1999-2006 and contain individual information on gender, date of birth, working hours, wages, tenure, and pension and early retirement entitlements. In principle, the dataset includes all individuals who contribute to the system at present and all individuals who have contributed in the past. The original administrative dataset is transformed into a so-called event-history dataset in order to facilitate the longitudinal analysis described in the next section.

The dataset is administered by Statistics Netherlands (CBS) and can be merged with other types of administrative data. For the analysis in this study, the administrative pension fund data is merged with the municipal population register (the so-called GBA Gemeentelijke BasisAdministratie voor persoonsgegevens) and the job registers. The administrative municipal data contains individual information on demographic and household characteristics. The job register is based on the national employment insurance register and on the registers of the tax authorities. The employment register contains individual information of all employees in the Netherlands, including working hours, wages, and employer information.

\subsection{Descriptive statistics}

We restrict the sample to individuals aged 50 to 64 . The number of observations increases from 150 thousand in 1999 to 330 thousand in 2006. The share of women in the sample is four out of five in 2006. Part-time employment is common in the health care sector. The

\footnotetext{
${ }^{11}$ The Dutch acronym OBU stands for 'OverBrUgginpensioen' ('Bridge pension').
} 
average hours worked equals two-thirds of a standard full-time job. At first, we divide participants into six groups: active (employed in the sector), stand-by-employee, sleeper (not employed in the sector), disabled, OBU-prepension and FLEX-prepension (Table 2). The number of 'sleepers', i.e. participants in the pension fund who are not building up additional pension rights and not yet receiving pension benefits, is large in 2002 for administrative reasons. Sleepers include workers who have moved to another firm or sector and unemployed workers, and they are informed about the status of their pension rights every five years.

Unemployed workers may receive regular unemployment benefits, additional unemployment benefits for elderly or social assistance. The percentage of individuals making use of the new (financially less attractive) FLEX scheme is practically negligible. For this reason the next section will ignore the FLEX scheme and focus on the transition (and financially more attractive) OBU scheme.

\begin{tabular}{|c|c|c|c|c|c|c|c|}
\hline \multirow[t]{2}{*}{ Table 2} & ket status & ividuals a & $50-64,199$ & 103, 2005- & & \multirow[b]{2}{*}{2005} & \multirow[b]{2}{*}{2006} \\
\hline & 1999 & 2000 & 2001 & 2002 & 2003 & & \\
\hline Observations & 154284 & 179903 & 179779 & 258962 & 250171 & 245377 & 326300 \\
\hline Status & $\%$ & & & & & & \\
\hline 1:=Active in sector & 75 & 74 & 77 & 64 & 73 & 87 & 70 \\
\hline 2:=Stand-by-employee ${ }^{b}$ & 4 & 3 & 3 & 3 & 3 & 3 & 2 \\
\hline 3:=Sleeper ${ }^{c}$ & 2 & 9 & 1 & 16 & 3 & 5 & 4 \\
\hline 4:=Disabled & 11 & 8 & 10 & 10 & 13 & 1 & 11 \\
\hline $5:=$ OBU-prepension ${ }^{d}$ & 7 & 6 & 9 & 7 & 9 & 4 & 12 \\
\hline $6:=$ FLEX-prepension ${ }^{\mathrm{e}}$ & 0 & 0 & 0 & 0 & 0 & 1 & 1 \\
\hline \multicolumn{8}{|c|}{$\begin{array}{l}\text { Sleeper are individuals under age } 65 \text { who have built up old-age pension rights in the past, but who are currently not working in the sector. } \\
\text { d Early retirees in the transitional (and financially attractive) scheme. } \\
\text { e Early retirees in the new (and financially less attractive) scheme. }\end{array}$} \\
\hline
\end{tabular}

\begin{tabular}{|c|c|c|c|c|c|}
\hline \multirow[t]{2}{*}{ Next ye } & \multicolumn{5}{|c|}{ Next year's labour market status of active individuals age $50-64,1999-2002,2005^{\mathrm{a}}$} \\
\hline & 1999 & 2000 & 2001 & 2002 & 2005 \\
\hline \multicolumn{6}{|l|}{ Next year's status ${ }^{b}$} \\
\hline $1:=$ Active in sector & 92.9 & 90.8 & 92.3 & 89.9 & 91.1 \\
\hline 2:= Stand-by-employee & 0.3 & 0.2 & 0.2 & 0.2 & 0.3 \\
\hline 3: = Sleeper & 2.1 & 2.9 & 2.3 & 3.8 & 3.3 \\
\hline 4: = Disabled & 0.9 & 1.3 & 1.3 & 1.3 & 0.2 \\
\hline 5: = OBU-prepension & 3.9 & 4.8 & 3.8 & 4.6 & 4.8 \\
\hline 6: = FLEX-prepension & 0.0 & 0.0 & 0.1 & 0.3 & 0.3 \\
\hline
\end{tabular}


Figure 3: Hazard rate into OBU early retirement by age for those being eligible ${ }^{\text {a }}$

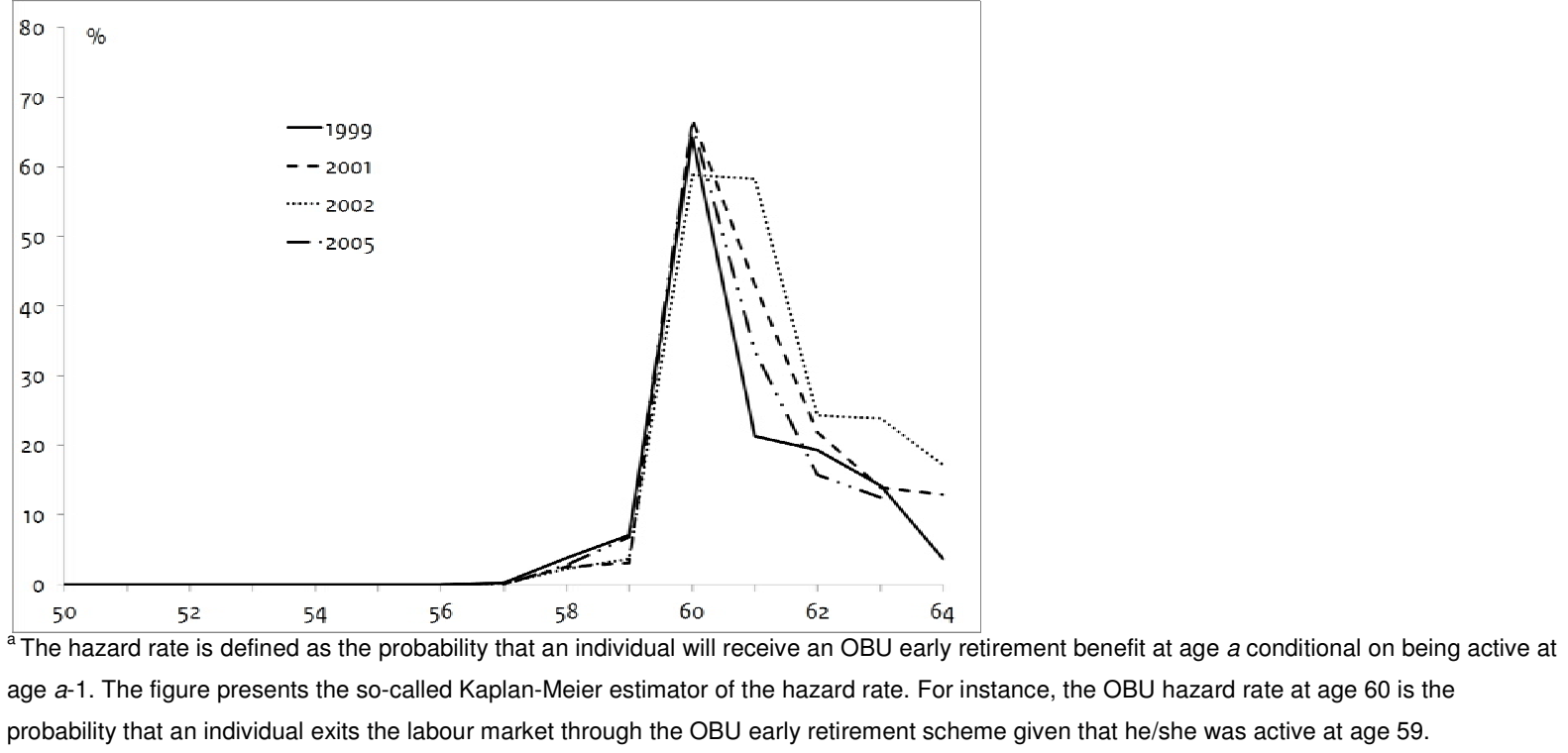

Figure 4: Hazard rate into disability by age for those being eligible (left) and non-eligible (right) to the attractive early retirement scheme $\mathrm{OBU}^{\mathrm{a}}$

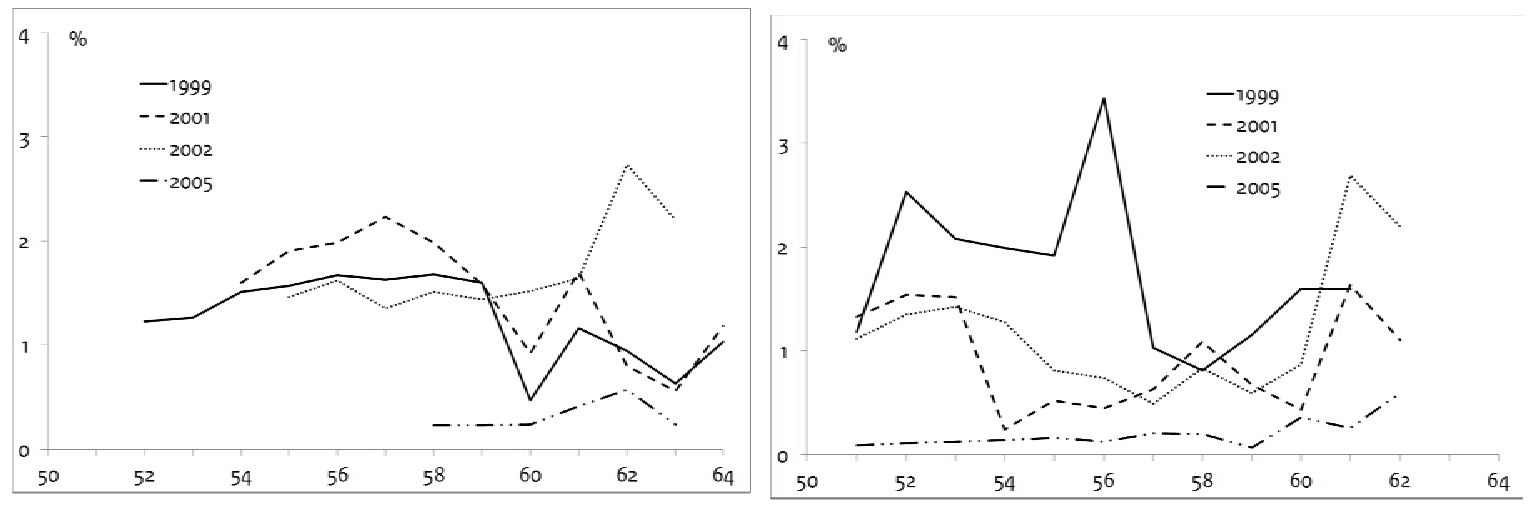

${ }^{\text {a }}$ See footnote of Figure 3.

In Table 3 we show 'flow probabilities' of active individuals to the six categories. Most workers between the ages of 50 and 65 , about $90 \%$ of them, are still active in the sector in the next year. The number of individuals starting to receive a disability pension has decreased substantially in 2005. This is in line with the reforms in the disability scheme. The number of individuals who start receiving the financially attractive OBU pension varies between 3.8 and $4.8 \%$ per year. The number of individuals who start receiving the new and financially less attractive FLEX pension increases slowly over time.

The option of retiring at age 60 seems attractive for many workers. About $70 \%$ of employees eligible for the financially attractive OBU pension at some age retire at the age of 60 , and this has hardly changed over time (Figure 3). Postponing retirement is financially unattractive. The implicit tax on continuing to work is high, as the benefit level hardly 
increases in case of postponement. From 2001 onwards it is allowed to receive the OBU pension and to be still working. Total income must however remain below $100 \%$ of the last earned income in order to receive the favourable fiscal treatment of the early retirement benefit. The first age at which workers retire is 58 . Workers who have access to the OBU pension at age 60 are allowed to retire part-time from age 58 with a benefit equalling half of the full benefit level. In that case they receive the partial benefit at ages 58-61, and from age 62 they receive the full benefit. This part-time retirement option seems flexible and may therefore be attractive. Yet, the conditional probability to retire at age 58 is small. This seems to be at odds with Kantarci and van Soest (2008), who show that many Dutch elderly have a stated preference for part-time retirement. A tentative explanation may be that many in the sector already work part-time (see Table A.1 of the appendix).

Compared to other exit routes, the OBU early retirement benefit is financially attractive. So individuals who are eligible for the OBU pension may have a relatively low probability to enter the disability insurance (DI) scheme. This is the hypothesis of substitute pathways: a preference for labour market exit leads to inflow into a benefit scheme, and having no access to one particular exit route will increase the probability of inflow into the alternative exit routes. The conditional probabilities of entering DI may suggest some substitution between exit routes for some years. For the years 1999 and 2001 the probability to enter DI decreased at age 60 for individuals having access to the OBU benefit (left panel of Figure 4). This is exactly the age at which inflow into the OBU schemes reaches a maximum, see previous figure. For the years 2002 and 2005 this drop in the inflow into DI does not occur however. Furthermore, the inflow into DI should differ in level and by age between those having and not having access to the OBU benefit in case of the substitute pathways (left and right panel of Figure 4). In particular, the inflow into DI should be higher for those who are not eligible for the OBU early retirement benefit. The level of inflow differs however between years, and a systematic difference is hard to recognise. To deal with the variation between the years, the next section will use statistical methods to test the hypotheses.

\section{Empirical analysis}

We model the transition in labour market status of active employees as a discrete variable with four possible outcomes: (1) continue working, (2) inflow into disability insurance, (3) early retirement with the financially attractive OBU scheme, or (4) 'other exit routes'. The latter category includes transitions to (unpaid) non-participation, unemployment, and work in another firm or sector. For early retirement with the OBU scheme, we aggregate full-time and 
part-time retirement. We use a Multinomial Logit Model to investigate the labour market transitions of active individuals for ages 58, 59, 60 and 61 separately:

$$
\operatorname{Pr}\left[y_{i, t+1}=j \mid y_{i, t}=\text { working }\right]=\frac{\exp \left(X_{i t} \beta_{j}+\gamma_{j} d_{i t}+W_{t} \delta_{j}\right)}{1+\sum_{j=1}^{4} \exp \left(X_{i t} \beta_{j}+\gamma_{j} d_{i t}+W_{t} \delta_{j}\right)}
$$

where $y_{i, t+1}$ is the observed outcome for individual $i$ at time $t+1$, and the vector $X_{i t}$ contains explanatory individual variables at time $t$, the dummy variable $d_{i t}$ indicates whether the individual is eligible for the OBU early retirement scheme at time $t$, while vector $\mathrm{W}_{t}$ contains dummies representing the year. The possible statuses at time $t+1$ are (1) 'working', (2) 'disability', and (3) 'OBU early retirement'; the reference category is (4) 'other exit routes'. The vectors of coefficients $\beta_{j}$ and $\delta_{j}$ and the coefficient $\gamma_{j}$ measure effects in comparison to effects on the probability to stop working in the health care sector through the 'other exit routes'-category. The unknown parameters are estimated by maximum likelihood. Results are presented in terms of 'marginal effects' on all categories (including 'else'), that is, the change in the probability of being in category $j$ as a result of a change in the explanatory variables.

The general claim in this study is that the reforms in DI and early retirement schemes, as discussed in Section 3, have led to a different functioning of the labour market. We expect that the policy reforms influence labour force participation and labour market exits in the health care sector. Our first hypothesis is that the inflow into early retirement and disability has decreased at the individual level, and so the probability to remain employed has increased. The parameter estimates for $\delta_{j}$ should show a significant decrease over the years for early retirement and disability, and a significant increase for continuing working. Our second hypothesis is that the reforms have lowered substitution between exit routes. In particular, disability insurance is not used anymore as a route for early retirement and the parameter estimate for $\gamma_{j}$, representing the eligibility to the OBU scheme, should be insignificant for disability. In case the pathways are not relevant anymore, which may be the case because of the reforms, not being eligible for the OBU scheme should in particular increase the probability to remain working.

The estimation results appear to confirm the first hypothesis as labour force participation has indeed increased over time. Table 4 summarizes some typical regression results for labour market transitions at age 60 , given that they are active in the previous period. The pattern of the year dummies shows that the probability of OBU early retirement 
has decreased over time, whereas labour market participation has increased. The probability to stay working in the same job has increased by 17\%-points between 2000 and 2005. Similar results are found for other ages; see Table A.2 of the appendix. At age 60, the inflow in disability has not significantly decreased over time, but for other ages the probability was significantly lower for 2005, see again Table A.2.

The estimation results also appear to confirm the second hypothesis. Eligibility for the OBU early retirement scheme does not affect the probability to enter DI. In case of substitute pathways, a non-eligible individual could opt for DI. But the results do not confirm such a substitution effect. The marginal effects in Table A. 2 show that nearly all individuals who are not yet eligible continue working. Earlier studies for the Netherlands have found evidence for a substitution effect (see section 3). Therefore our results support the hypothesis that the reforms have halted substitution, and DI is not used for early retirement anymore.

Besides the hypotheses we have tested, the results show some additional insights. First, eligibility to OBU early retirement does not affect the transition probabilities at age 58 . So part-time early retirement with does not seem to be that attractive for workers in the sector. At age 59, the dummies for eligibility are statistically significant for continuing working and inflow into the OBU scheme, but the size of the effect is small. At ages 60 and 61 the marginal effect of eligibility is large. Being eligible for the OBU benefit increases the probability to claim the benefit by more than $60 \%$-points. This is likely related to the implicit taxes on continued work (see previous section). Second, individual characteristics clearly matter for exit behaviour. Women are less likely to continue working and are more likely to retire with the OBU scheme. Individuals with a partner are also less likely to continue working, while individuals with children are more likely to continue working.

\begin{tabular}{|c|c|c|c|c|c|c|}
\hline \multicolumn{7}{|c|}{ Marginal effects for employees at age 60 over the period $1999-2002 \& 2005^{a}$} \\
\hline Outcome variable & still working & & Inflow-DI & & Inflow-OBU & \\
\hline Eligible at age $60^{\mathrm{b}}$ & $-0.618^{*}$ & $(0.006)$ & 0.001 & $(0.001)$ & $0.636^{*}$ & $(0.005)$ \\
\hline 2000 & $-0.093^{*}$ & $(0.011)$ & $0.012^{*}$ & $(0.004)$ & $0.094^{*}$ & $(0.011)$ \\
\hline 2001 & 0.021 & $(0.011)$ & $0.008^{*}$ & $(0.003)$ & 0.002 & $(0.011)$ \\
\hline 2002 & $0.039^{*}$ & $(0.011)$ & $0.009^{*}$ & $(0.003)$ & $-0.027^{\star}$ & $(0.009)$ \\
\hline 2005 & $0.081^{*}$ & $(0.010)$ & -0.002 & $(0.002)$ & $-0.030^{*}$ & $(0.010)$ \\
\hline woman & $-0.087^{*}$ & $(0.008)$ & $0.002^{*}$ & $(0.001)$ & $0.088^{*}$ & $(0.009)$ \\
\hline partner & $-0.122^{*}$ & $(0.007)$ & -0.001 & $(0.001)$ & $0.113^{*}$ & $(0.007)$ \\
\hline children & $0.078^{*}$ & $(0.008)$ & 0.001 & $(0.001)$ & $-0.074^{*}$ & $(0.008)$ \\
\hline
\end{tabular}




\section{Conclusion}

The institutions facilitating early retirement in the Netherlands have been reshaped during the past two decades. Mandatory occupational early retirement schemes were abandoned, and partially integrated into the old-age pension system. Early retirement benefits through the pension system are actuarially fair, and the replacement rate is now lower. The Disability Insurance (DI) scheme was reformed almost simultaneously with the early retirement schemes. Several measures were taken to prevent inflow into DI, including financial incentives for both employers and employees and more stringent reintegration obligations in case of sickness. The objective of this study is to assess whether the policies have been successful in decreasing labour market exit through both alternative exit routes.

The empirical literature shows that there is ample evidence for substitute pathways into early retirement in the past in the Netherlands as well as in several other countries. In other words, a general preference for early retirement existed and individual workers had a 'choice' between several exit routes, including 'official' early retirement, disability and unemployment. The policy reforms of the last decades may, however, have reduced such substitution between alternative exit routes. In this study, we assess whether administrative data in the health care sector are consistent with the hypothesis that the participation rate of elderly has increased and that DI is no longer used as an alternative exit route. Our empirical analysis provides support for the hypothesis that employment rates of older individuals have increased. Moreover, the empirical results are consistent with the hypothesis that DI is no longer used as an alternative early exit route. The reforms seem to have prevented substitution from early retirement schemes towards the disability scheme.

Overall policies established in the Netherlands to prevent early labour market exit have been successful. Participation incentives have improved and the costs of providing early exit routes have been reduced. This does however not necessarily prove that the Dutch policies are optimal in the sense that well-being has increased. Workers are likely to be risk averse, and they have a preference for reasonable labour market exit options in case of a substantial loss in skills, for example due to health or technology shocks. The development of tools for welfare analysis, see Cremer et al. (2004, 2008) and Zaidi and Whitehouse (2009), is therefore necessary to assess the effectiveness of policy. 


\section{References}

L. Aarts and P. de Jong, 1992, Economic Aspects of Disability Behavior, North Holland, Amsterdam.

D. Autor and M. Duggan, 2003, The Rise in the Disability Rolls and the Decline in Unemployment, Quarterly Journal of Economics, Vol. 118, pp. 157-205.

N. Barr and P. Diamond, 2009, Reforming pensions: Principles, analytical errors and policy directions, International Social Security Review, Vol. 62, pp. 5-29.

L. Behaghel, D. Blanchet, T. Debrand, and M. Roger, 2011, Disability and social security reforms: The French case, Working paper 2011-02, Paris School of Economics.

H. Benitez-Silva, R. Disney, and S. Jimenez-Martin, 2010, Disability, capacity for work and the business cycle: An international perspective, Economic Policy, Vol. 25, pp. 483-536.

D. Black, K. Daniel, and S. Sanders, 2002, The impact of the economic conditions on participation in disability programs: evidence from the coal boom and bust, American Economic Review, Vol. 92, pp. 27-50.

J. Bound, M. Schoenbaum, T. Stinebrickner, and T. Waidmann, 1991, The dynamic effects of health on the labor force transitions of older workers, Labour Economics, Vol. 6, pp.179-202.

H. Cremer, J. Lozachmeur and P. Pestieau, 2004, Social Security, Retirement Age and Optimal Income Taxation, Journal of Public Economics, Vol. 88, pp. 2259-2281.

H. Cremer, J. Lozachmeur and P. Pestieau, 2008, Social Security and Retirement Decision, a Positive and a Normative Approach, Journal of Economic Surveys, Vol. 22(2), pp. 213-237.

M. Duggan, P. Singleton, and J. Song, 2007, Aching to retire? The rise in the full retirement age and its impact on the social security disability rolls, Journal of Public Economics, Vol. 91, pp. 1327-1350. 
R. Duval, 2010, The retirement effects of old-age pension and early retirement schemes in OECD countries, mimeo, Department of Economics, OECD.

R. Euwals, D. van Vuuren, and R. Wolthoff, 2010, Early retirement behaviour in the Netherlands, De Economist, Vol. 158, pp. 209-236.

R. Euwals, E. Trevisan, and A. van Vuren, 2010, Labour Market Exit in the Health Care Sector: First Results from Administrative Data, Netspar Discussion Paper 05/2010-016.

R. Euwals, M. Knoef, and D. van Vuuren, 2011, The trend in female labour force participation: What can be expected for the future? Empirical Economics, 40, 729-753.

J. Gruber and D. Wise, 2004, Social Security and Retirement around the World: Microestimation, University of Chicago Press.

J. Gruber and D. Wise, 2010, Social Security Programs and Retirement around the World: The Relationship to Youth Employment, University of Chicago Press.

W. Hassink, J. van Ours, and G. Ridder, 1997, Dismissal through Disability, De Economist, Vol. 145, pp. 29-46.

A. Heyma, 2004, A structural dynamic analysis of retirement behaviour in the Netherlands, Journal of Applied Econometrics, Vol. 19, pp. 739-759.

A. Kapteyn and K. de Vos, 1999, Social Security and Retirement in the Netherlands, in: J. Gruber and D. Wise (eds.), Social Security and retirement around the world, Chicago University Press, pp. 269-304.

M. Kerkhofs, M. Lindeboom, and J. Theeuwes, 1999, Retirement, Financial Incentives and Health, Labour Economics, Vol. 6, pp. 203-227

M. Kohli and M. Rein, 1991, The changing balance of work and retirement, In: M. Kohli, M. Rein, A. Guillemard and H.v. Gunsteren (eds.), Time for Retirement, Cambridge University Press, pp. 1-35. 
P. Koning and D. van Vuuren, 2007, Hidden Unemployment in Disability Insurance, Labour, Vol. 21, pp. 611-636.

P. Koning and D. van Vuuren, 2010, Disability Insurance and Unemployment Insurance as Substitute Pathways, Applied Economics, Vol. 42(5), pp. 575-588.

M. Larsen and P.J. Pedersen, 2008, Pathways to early retirement in Denmark, $1984-2000$. International Journal of Manpower, Vol. 29(5), pp. 384 - 409.

O. Mitchell and J. Phillips, 2000, Retirement Responses to Early Social Security Benefit Reductions, NBER Working Paper 7963.

R. Riphahn, 1997, Disability Retirement and Unemployment—Substitute Pathways for Labour Exit? An Empirical Test for the Case of Germany, Applied Economics, Vol. 29, pp. $551-561$.

T. Schils, 2008, Early Retirement in Germany, the Netherlands, and the United Kingdom: A Longitudinal Analysis of Individual Factors and Institutional Regimes, European Sociological Review, Vol. 24(3), pp. 315-329.

A. van Vuren and D. van Vuuren, 2007, Financial incentives in Disability Insurance in the Netherlands, De Economist, Vol. 155(1), pp. 73-98.

E. Westerhout, 1996, Hidden Unemployment in Dutch Disability Schemes, CPB Report 2, pp. 24-29.

I. Woittiez, M. Lindeboom, and J. Theeuwes, 1994, Labour Force Exit Routes of the Dutch Elderly: A Discrete Choice Model, in: L. Bovenberg (ed.), The Economics of Pensions: The Case of the Netherlands, Rotterdam: Ocfeb, pp. 1-12.

A. Zaidi and E. Whitehouse, 2009, Should Pension Systems Recognize "Hazardous and Arduous Work"? OECD Social, Employment and Migration Working Papers, No. 91, OECD. 


\section{Appendix: Sample means and estimation results}

\begin{tabular}{|c|c|c|c|c|c|c|c|c|}
\hline Period: 1999-2002; 2005 & \multicolumn{4}{|c|}{ still working } & \multicolumn{4}{|c|}{ inflow-DI } \\
\hline variable $\backslash$ age & 58 & 59 & 60 & 61 & 58 & 59 & 60 & 61 \\
\hline Eligible at age 60 & 83.3 & 82.5 & 59.3 & 34.1 & 89.3 & 84.8 & 82.4 & 50.5 \\
\hline Eligible at age 61 & 1.6 & 2.0 & 5.7 & 12.0 & 1.8 & 2.7 & 4.2 & 13.9 \\
\hline Eligible at age 62 & 1.4 & 1.2 & 4.2 & 8.6 & 2.2 & 2.5 & 1.4 & 8.9 \\
\hline Eligible at age 63 & 1.5 & 1.3 & 2.5 & 5.9 & 2.0 & 3.2 & 2.3 & 5.0 \\
\hline Eligible at age 64 & 1.3 & 1.4 & 2.8 & 3.9 & 0.2 & 2.0 & 1.4 & 6.9 \\
\hline 1999 & 14.2 & 13.0 & 13.8 & 13.0 & 14.9 & 14.0 & 7.5 & 10.9 \\
\hline 2000 & 16.8 & 15.2 & 11.7 & 15.4 & 26.6 & 27.0 & 27.8 & 28.7 \\
\hline 2001 & 17.9 & 17.4 & 16.3 & 15.9 & 25.8 & 24.8 & 23.1 & 18.8 \\
\hline 2002 & 19.7 & 20.9 & 19.9 & 19.1 & 28.2 & 30.0 & 31.0 & 33.7 \\
\hline 2005 & 31.4 & 33.5 & 38.3 & 36.6 & 4.5 & 4.2 & 10.6 & 7.9 \\
\hline woman & 77.5 & 76.8 & 72.9 & 70.4 & 84.6 & 89.2 & 83.3 & 90.1 \\
\hline immigrant & 12.4 & 12.2 & 14.4 & 16.1 & 11.4 & 10.8 & 12.5 & 13.4 \\
\hline partner & 76.6 & 75.9 & 70.0 & 65.8 & 70.2 & 75.5 & 74.1 & 54.5 \\
\hline Children & 25.9 & 22.6 & 22.6 & 21.5 & 21.9 & 21.6 & 21.8 & 9.9 \\
\hline small job (< 40\%) & 18.4 & 18.9 & 22.1 & 26.3 & 19.3 & 23.3 & 31.9 & 33.7 \\
\hline middle job & 40.8 & 40.2 & 37.2 & 34.6 & 46.6 & 46.7 & 36.2 & 35.6 \\
\hline large job (> 80\%) & 40.8 & 40.9 & 40.7 & 39.1 & 34.1 & 30.0 & 31.9 & 30.7 \\
\hline \multirow[t]{2}{*}{ Number of observations } & 48305 & 41814 & 14286 & 6545 & 507 & 408 & 216 & 101 \\
\hline & \multicolumn{3}{|c|}{ inflow-OBU } & & \multicolumn{4}{|c|}{ else } \\
\hline variable $\backslash$ age & 58 & 59 & 60 & 61 & 58 & 59 & 60 & 61 \\
\hline Eligible at age 60 & 98.7 & 98.8 & 98.0 & 82.9 & 69.8 & 69.4 & 82.5 & 37.6 \\
\hline Eligible at age 61 & 0.1 & 0.4 & 0.9 & 13.9 & 2.9 & 3.1 & 2.0 & 9.9 \\
\hline Eligible at age 62 & 0.1 & 0.2 & 0.2 & 2.2 & 2.8 & 2.4 & 1.1 & 7.1 \\
\hline Eligible at age 63 & 0.1 & 0.2 & 0.1 & 0.1 & 3.5 & 1.7 & 1.1 & 3.9 \\
\hline Eligible at age 64 & 0.2 & 0.0 & 0.1 & 0.1 & 2.1 & 2.4 & 1.0 & 3.3 \\
\hline 1999 & 20.1 & 17.7 & 14.8 & 5.6 & 19.2 & 15.7 & 6.8 & 3.1 \\
\hline 2000 & 22.0 & 20.3 & 18.8 & 27.7 & 20.7 & 26.1 & 5.7 & 9.3 \\
\hline 2001 & 16.1 & 9.8 & 18.6 & 15.8 & 19.4 & 17.7 & 3.9 & 10.4 \\
\hline 2002 & 14.6 & 13.9 & 12.0 & 27.3 & 35.6 & 34.7 & 77.6 & 57.0 \\
\hline 2005 & 27.2 & 38.3 & 35.8 & 23.6 & 5.1 & 5.8 & 6.0 & 20.2 \\
\hline woman & 73.1 & 74.1 & 79.0 & 77.5 & 74.9 & 73.6 & 77.4 & 66.4 \\
\hline immigrant & 8.9 & 10.6 & 11.1 & 14.1 & 13.0 & 14.1 & 11.0 & 15.3 \\
\hline partner & 74.8 & 78.5 & 79.5 & 74.0 & 79.6 & 77.0 & 79.4 & 70.7 \\
\hline Children & 22.0 & 18.5 & 16.3 & 18.9 & 22.4 & 19.2 & 17.7 & 19.4 \\
\hline small job (< 40\%) & 9.7 & 15.4 & 18.4 & 17.1 & 28.5 & 29.6 & 24.2 & 25.6 \\
\hline middle job & 34.9 & 37.2 & 41.6 & 41.7 & 39.1 & 36.3 & 45.3 & 37.1 \\
\hline large job (> 80\%) & 55.4 & 47.4 & 40.0 & 41.2 & 32.4 & 34.1 & 30.5 & 37.3 \\
\hline Number of observations & 1346 & 2245 & 20756 & 3373 & 1405 & 1309 & 3444 & 777 \\
\hline
\end{tabular}




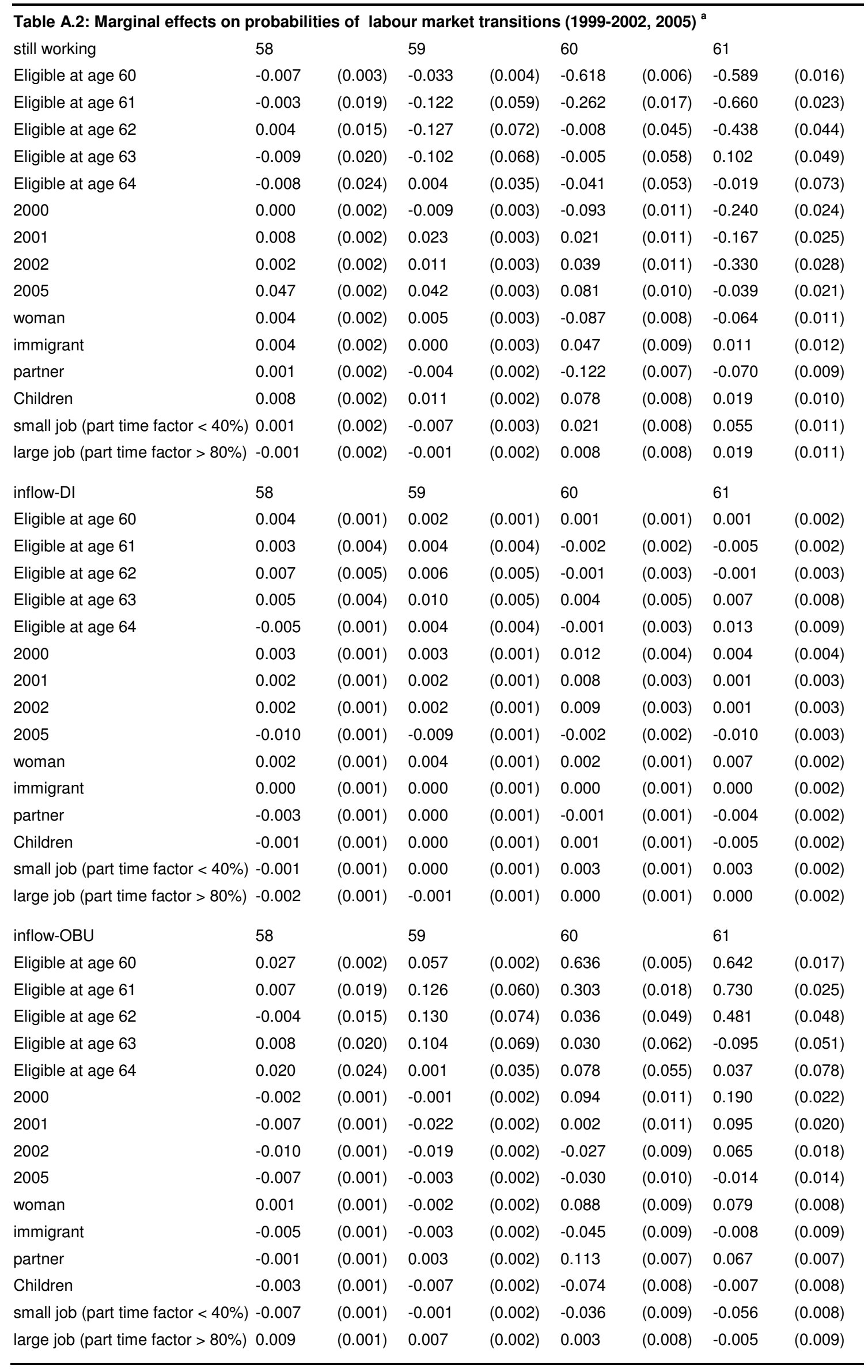




\begin{tabular}{lllllllll}
\hline else & 58 & & 59 & & 60 & & 61 & \\
Eligible at age 60 & -0.024 & $(0.003)$ & -0.026 & $(0.003)$ & -0.019 & $(0.003)$ & -0.055 & $(0.005)$ \\
Eligible at age 61 & -0.007 & $(0.002)$ & -0.009 & $(0.002)$ & -0.040 & $(0.003)$ & -0.065 & $(0.004)$ \\
Eligible at age 62 & -0.006 & $(0.002)$ & -0.009 & $(0.002)$ & -0.027 & $(0.005)$ & -0.043 & $(0.007)$ \\
Eligible at age 63 & -0.004 & $(0.002)$ & -0.012 & $(0.002)$ & -0.029 & $(0.005)$ & -0.014 & $(0.012)$ \\
Eligible at age 64 & -0.007 & $(0.002)$ & -0.009 & $(0.002)$ & -0.036 & $(0.004)$ & -0.031 & $(0.010)$ \\
2000 & -0.001 & $(0.001)$ & 0.007 & $(0.002)$ & -0.013 & $(0.004)$ & 0.046 & $(0.022)$ \\
2001 & -0.004 & $(0.001)$ & -0.003 & $(0.002)$ & -0.031 & $(0.003)$ & 0.071 & $(0.025)$ \\
2002 & 0.005 & $(0.002)$ & 0.007 & $(0.002)$ & 0.224 & $(0.011)$ & 0.263 & $(0.035)$ \\
2005 & -0.030 & $(0.001)$ & -0.030 & $(0.002)$ & -0.049 & $(0.004)$ & 0.063 & $(0.020)$ \\
woman & -0.007 & $(0.002)$ & -0.007 & $(0.002)$ & 0.009 & $(0.002)$ & -0.022 & $(0.007)$ \\
immigrant & 0.001 & $(0.002)$ & 0.004 & $(0.002)$ & -0.002 & $(0.003)$ & -0.003 & $(0.007)$ \\
partner & 0.003 & $(0.001)$ & 0.001 & $(0.001)$ & 0.009 & $(0.002)$ & 0.006 & $(0.006)$ \\
Children & -0.004 & $(0.001)$ & -0.005 & $(0.001)$ & -0.005 & $(0.002)$ & -0.007 & $(0.006)$ \\
small job (part time factor < 40\%) & 0.007 & $(0.002)$ & 0.009 & $(0.002)$ & 0.012 & $(0.003)$ & -0.002 & $(0.007)$ \\
large job (part time factor $>80 \%)$ & -0.006 & $(0.001)$ & -0.005 & $(0.001)$ & -0.011 & $(0.003)$ & -0.015 & $(0.007)$ \\
a Standard errors are given between parentheses. & & & & & & & \\
\hline
\end{tabular}

